\title{
Enhancement of radiation response with combined Ganoderma lucidum and Duchesnea chrysantha extracts in human leukemia HL-60 cells
}

\author{
KUG CHAN KIM, HYUN JEONG JUN, JIN SIK KIM and IN GYU KIM
}

Department of Radiation Biology, Nuclear Environmental Safety Research Center, Korea Atomic Energy Research Institute, 150 Dukjin-dong, Yuseong, Daejeon 305-353, Korea

Received December 3, 2007; Accepted January 15, 2008

\begin{abstract}
We previously demonstrated that combined treatment with extracts of the medicinal mushroom Ganoderma lucidum and the herb Duchesnea chrysantha (GDE) significantly suppresses cell growth and selectively induces apoptosis in human leukemia HL-60 cells, but not in normal cells. GDE's mechanism of action and its activity against HL-60 cells suggest that it could be suitable for the combined-modality treatment of hematological malignancies. In the present study, we examined whether treatment with a combination of GDE and ionizing radiation enhances the therapeutic effect. We demonstrated that, when used in combination with radiation at a clinically relevant dose of 2 Gy, GDE further suppressed cell proliferation and induced apoptosis as well as micronuclei formation in HL-60 cells, leading to increased cell death. Furthermore, GDE pretreatment not only reduced radiation-induced $\mathrm{G}_{2} / \mathrm{M}$-phase arrest, but also induced $\mathrm{G}_{1}$-phase arrest. These events are associated with the inhibition of cyclin-dependent kinase 1 (CDK1) phosphorylation and the dephosphorylation of retinoblastoma protein (pRB). Collectively, these data show that combined treatment with GDE and radiation enhances radiation-induced apoptosis and overall cell death. These findings may be clinically relevant and suggest a novel therapeutic strategy for increasing the efficacy of radiotherapy.
\end{abstract}

\section{Introduction}

Currently, radiotherapy is a mainstay of cancer therapy and is used to treat $\sim 50 \%$ of the cancer population. However, the

Correspondence to: Dr In Gyu Kim, Department of Radiation Biology, Nuclear Environmental Safety Research Center, Korea Atomic Energy Research Institute, 150 Dukjin-dong, Yuseong, Daejeon 305-353, Korea

E-mail: igkim@kaeri.re.kr

Key words: leukemia, ionizing radiation, apoptosis, Ganoderma lucidum, Duchesnea chrysantha application and efficacy of radiotherapy are limited by damage to normal tissue. Radiation can produce cell death by one of two mechanisms: apoptosis or necrosis (1). Apoptosis is a major form of cell death, and is a mechanism of radiationand/or chemotherapy-induced cell death in human hematological malignancies. An increase of the apoptotic threshold in lymphoma and leukemia is a mechanism of resistance to treatment (2). In addition to apoptosis, tumor cells can be effectively eliminated after DNA damage by non-apoptotic mechanisms, such as necrosis, senescence, autophagy, and mitotic catastrophe (3). As the induction mechanism of apoptosis by radiation may differ from the mechanism of classical clonogenic cell death by radiation, it is possible that these two end points of radiation action may be differentially modifiable. Recently, the combination of radiation with chemotherapy or molecular-targeted agents has become a common strategy for the treatment of advanced cancer (4-6). Biologically, chemotherapeutic agents interact with radiation through a number of mechanisms, including an increase in initial radiation damage, the inhibition of cellular repair, cellcycle redistribution, and the inhibition of tumor cell regeneration (4). Unfortunately, the available therapeutic agents have been limited owing to their associated high toxicity, lack of tumor selectivity, and low efficacy. Therefore, the development of agents that will minimize toxicity while maintaining efficacy is required. Increasing the incidence of radiation-induced apoptosis selectively in tumor cells may thus result in greater radiosensitivity and an improvement in treatment outcomes. Another possible way to improve therapeutic radiosensitivity may be through modulation of the cell cycle, as cell-cycle regulation is perhaps the most important determinant of ionizing radiation sensitivity.

The medicinal mushroom Ganoderma lucidum and the herb Duchesnea chrysantha have been used traditionally in East Asia for the prevention and treatment of various diseases, including cancer. Ganoderma lucidum, which belongs to the Polyporaeae family, contains a large variety of biologically active polysaccharides and triterpenes with antitumor activities (7). Currently, $\sim 100$ different triterpenoids, which have a lanostane skeleton, are known to occur in Ganoderma lucidum alone $(8,9)$. Recent studies have shown that Ganoderma lucidum induces apoptosis, inhibits cell proliferation, and suppresses cell migration of highly invasive human breast and prostate cancer cells $(10,11)$. The 
medicinal plant Duchesnea chrysantha, which belongs to the Rosaceae family, contains biologically active lectin and polysaccharides with antioxidative (12) and immunostimulatory properties (G.J. Jeong, unpublished data). The physiologically active compounds from Duchesnea chrysantha are known to exert cytotoxic activities in human cancer cells (13).

A previous study in this laboratory demonstrated that combined treatment with extracts of the medicinal mushroom Ganoderma lucidum and the herb Duchesnea chrysantha (GDE) causes an enhanced induction of mitochondrial damage and apoptosis as well as growth inhibition in human leukemia HL-60 cells (14). Moreover, the combination of these extracts was selectively toxic to the leukemic cells, whereas no cytotoxic effect was observed in the normal human peripheral blood mononuclear cells, raising the possibility that this strategy has the potential for therapeutic selectivity. In this study, we tested whether treatment with a combination of GDE and ionizing radiation (IR) would enhance the therapeutic effect, as these extracts contain biologically active compounds responsible primarily for antitumor activities. The current study was performed with the use of radiation at a clinically relevant dose of $2 \mathrm{~Gy}$. The TP53-deficient human promyelocytic leukemia cell line HL-60 was used as an in vitro model to test the possible interaction between GDE and IR. We demonstrate here that the combination of GDE and IR is more effective than either modality alone in reducing the proliferative potential of HL-60 cells and in increasing cell death. Taken together, these findings suggest that this combination merits further investigation as a potential therapeutic agent for the treatment of cancer.

\section{Materials and methods}

Preparation of Duchesnea and Ganoderma extracts. The extracts of Duchesnea chrysantha and Ganoderma lucidum were isolated and characterized by the method described by Kim et al (12) and Zhu et al (15), respectively. Briefly, for the preparation of Duchesnea extracts, the whole parts (i.e. leaves, roots and stems) of Duchesnea chrysantha were extracted with boiling water. The aqueous solution was extracted with an equal volume of chloroform and then evaporated to remove the chloroform. The water-soluble polysaccharide-enriched fraction was isolated from the concentrated extract in two steps by precipitation with ethanol. After removal of the fraction precipitated with an equal volume of ethanol, the water-soluble polysaccharides, precipitated by the addition of a further 3 volumes of ethanol, were collected and lyophilized. For the preparation of Ganoderma extracts, the fruiting bodies of Ganoderma lucidum were boiled with water, and then the polysaccharide fraction was removed by ethanol precipitation as described above. The remaining aqueous solution was then partitioned between water and chloroform. The chloroform layer containing a triterpenoid-enriched fraction was evaporated under reduced pressure and then lyophilized. The presence of triterpenes was characterized by silica gel thin-layer chromatography. In our experiments, we used the polysaccharide-enriched fraction of the Duchesnea extract and the triterpenoid-enriched fraction of the Ganoderma extract.
All lyophilized samples were dissolved, sterilized by passage through a $0.22-\mu \mathrm{m}$ filter, and stored at $-20^{\circ} \mathrm{C}$ until use.

Cell culture, reagents, and irradiation conditions. Human promyelocytic leukemia HL-60 cells were grown at $37^{\circ} \mathrm{C}$ in a humidified atmosphere containing $5 \% \mathrm{CO}_{2}$ in RPMI-1640 medium supplemented with $10 \%$ fetal bovine serum, penicillin (100 IU/ml), and streptomycin (100 $\mu \mathrm{g} / \mathrm{ml})$. HL-60 cells were plated at a density of $1 \times 10^{5}$ cells $/ \mathrm{ml}$ in a T-25 flask $18 \mathrm{~h}$ before irradiation. Unless otherwise indicated, Duchesnea extract $(100 \mu \mathrm{g} / \mathrm{ml})$ plus Ganoderma extract $(150 \mu \mathrm{g} / \mathrm{ml})$ were added to cultures at least $1 \mathrm{~h}$ before irradiation. The cells were irradiated with a dose of 2 Gy with the use of a ${ }^{60} \mathrm{Co} \gamma$-ray source at a dose rate of $0.2 \mathrm{~Gy} / \mathrm{min}$.

Survival assays. For a short-term cell survival assay, cell survival was determined by the 3-(4,5-dimethylthiazol-2-yl)5-(3-carboxymethoxy-phenyl)-2-(4-sulfophenyl)-2H-tetrazolium, inner salt (MTS) assay or by trypan blue exclusion. For the MTS assay, the cytotoxicity of the extracts was assessed with the use of a cell proliferation assay developed by Promega (CellTiter $96^{\circledR}$ AQueous One Solution Cell Proliferation Assay). Briefly, 2x104 exponentially growing cells were seeded in 96-well microculture plates with or without extract treatment in a volume of $100 \mu \mathrm{l}$ and irradiated as described above. After a 48-h incubation at $37^{\circ} \mathrm{C}, 20 \mu 1$ of MTS was added to each well, and the samples were incubated for a further $2 \mathrm{~h}$ at $37^{\circ} \mathrm{C}$. Plates were analyzed on a microtiter plate reader at $492 \mathrm{~nm}$. For the trypan blue exclusion assay, cells were cultured and treated in the same way. They were harvested, and trypan blue dye solution was added to the cell suspension. Total cell counts and viable cell numbers were determined with a hemocytometer. For a long-term cell survival assay, a clonogenic assay was performed in soft agar cultures, as previously described (16). Briefly, 1,000 cells were plated in $1 \mathrm{ml}$ of $0.3 \%$ agar in RPMI-1640 medium containing $15 \%$ fetal bovine serum, and GDE was added $1 \mathrm{~h}$ before irradiation. After irradiation with a dose of $2 \mathrm{~Gy}$, colonies, defined as groups of $\geq 50$ cells, were scored after 10-12 days of incubation; clonogenic survival was expressed as a percentage relative to the untreated controls.

Flow cytometric detection of cell cycle and apoptosis. Untreated control and irradiated cells were collected, washed with cold phosphate-buffered saline (PBS), and fixed with $70 \%$ ethanol at $4^{\circ} \mathrm{C}$ for at least $1 \mathrm{~h}$. Fixed cells were washed with PBS and treated with RNase $\left(30 \mathrm{~min}\right.$ at $\left.37^{\circ} \mathrm{C}, 100 \mu \mathrm{g} / \mathrm{ml}\right)$, and their DNA was stained with propidium iodide (PI; $50 \mu \mathrm{g} / \mathrm{ml})$. The DNA content was measured with a FACScan (EPICS XL; Beckman Coulter). A minimum of 10,000 cells was counted for each sample. The percentage of cells in each phase of the cell cycle was analyzed with the use of Phoenix Multicycle software (Phoenix Flow Systems). The level of apoptosis was quantified by measuring the number of subdiploid (sub- $\mathrm{G}_{1}$ ) cells stained with PI as described above.

To further confirm the results of apoptosis analysis, we stained cells with fluorescein isothiocyanate-conjugated annexin V and PI, with the use of the Annexin V-FITC Apoptosis Detection Kit (Alexis Biochemicals) according to 
the manufacturer's instructions. For these experiments, $1-2 \times 10^{5}$ cells per condition were harvested. Analysis was carried out with the use of a Coulter EPICS XL flow cytometer.

Micronuclei assay. The cells were seeded in duplicate into T-25 flasks and treated either with the combination of GDE+1 Gy irradiation or $1 \mathrm{~Gy}$ alone for up to $48 \mathrm{~h}$. Final concentrations of GDE were $75 \mu \mathrm{g} / \mathrm{ml}$ Duchesnea extract plus $100 \mu \mathrm{g} / \mathrm{ml}$ Ganoderma extract. GDE was added to the medium $1 \mathrm{~h}$ before irradiation. Cytochalasin B (Sigma) was added at a final concentration of $3 \mu \mathrm{g} / \mathrm{ml}$ for $24 \mathrm{~h}$ culturing before cell harvest. Cells were fixed into fixative solution (methanol:acetic acid, 3:1). Slides were made by dropping the cell suspension on clean object glasses and staining the cells in Giemsa solution. A total of 1,000 binucleated cells were scored for the presence of micronuclei (17).

Detection of mitochondrial membrane potential. HL-60 cells were treated with radiation ( $2 \mathrm{~Gy}$ ) alone, or the combination of GDE and radiation, for up to $48 \mathrm{~h}$. The integrity of mitochondrial membranes was measured with the use of a JC-1 probe (Molecular Probes) as described (18). The percentage of red fluorescence (FL3) was estimated by flow cytometry.

Measurement of caspase-3 activity. Caspase-3 activity was measured with the use of the Caspase-3 Colorimetric Assay Kit (Alexis Biochemicals) according to the recommended protocol. Briefly, 7x $10^{5}$ exponentially growing HL-60 cells in RPMI-1640 medium were treated with the extract at the indicated concentration for $48 \mathrm{~h}$ at $37^{\circ} \mathrm{C}$. The cell pellet ( $1-5 \times 10^{6}$ cells) was re-suspended in $50 \mu 1$ of chilled cell lysis buffer, and then incubated on ice for $10 \mathrm{~min}$. The cell lysate was spun at $10,000 \mathrm{x} \mathrm{g}$ for $1 \mathrm{~min}$, and the supernatant was used to estimate the caspase activity. The equivalent of $100 \mu \mathrm{g}$ of protein from the cell lysate was pipetted into each well of a 96-well plate; then $50 \mu 1$ of $2 \mathrm{X}$ reaction buffer (containing $10 \mathrm{mmol} / \mathrm{l}$ dithiothreitol) and $5 \mu \mathrm{l}$ of the $4 \mathrm{mmol} / \mathrm{l} \mathrm{DEVD-}$ pNA substrate were added to each sample. After $1 \mathrm{~h}$ of incubation at $37^{\circ} \mathrm{C}$, the formation of $p$-nitroanilide was measured at $405 \mathrm{~nm}$ with the use of a microtiter plate reader.

Subcellular fractionation and Western blot analysis. Cells were re-suspended in cell lysis buffer (1\% Triton X-100, $0.15 \mathrm{~mol} / 1 \mathrm{NaCl}, 10 \mathrm{mmol} / \mathrm{l}$ Tris- $\mathrm{HCl}, \mathrm{pH} 7.4,1 \mathrm{mmol} / \mathrm{l}$ EDTA, $1 \mathrm{mmol} / 1$ phenylmethylsulfonyl fluoride, $10 \mu \mathrm{g} / \mathrm{ml}$ each of leupeptin and pepstatin A) and then incubated on ice for $20 \mathrm{~min}$. The cell lysates were centrifuged at $10,000 \mathrm{x} \mathrm{g}$ for $10 \mathrm{~min}$ at $4^{\circ} \mathrm{C}$, and the supernatants were used for Western blot analysis. The protein concentration was determined with the use of the Micro Protein Determination Kit (Sigma Chemical). Nuclear and cytoplasmic extracts were prepared by using the Nuclear Extraction Kit (Chemicon) according to the manufacturer's protocol. For the immunoblotting analysis, proteins in whole lysates, nuclear fractions, or cytoplasmic fractions were run on sodium dodecylsulfate-polyacrylamide gel and then transferred onto polyvinylidene difluoride membrane. Non-specific binding was blocked by incubation with $5 \%$ nonfat milk in Tris-buffered saline containing $0.1 \%$
Tween 20 (TBST) for $1 \mathrm{~h}$ at room temperature. The blots were incubated in fresh blocking solution at room temperature for $1 \mathrm{~h}$ with primary antibodies directed against the following proteins: Bcl-2 (Santa Cruz Biotechnology), Bax and caspase-3 (Upstate Biotechnology), Smac/DIABLO (BD Pharmingen), phospho-Akt (Ser473) (Cell Signaling Technology), under-phosphorylated retinoblastoma (BD Pharmingen), Cdk4 and Cdk2 (Santa Cruz Biotechnology), Cdc2 and phospho-cde2 (Tyr 15) (Cell Signaling Technology), cyclin E (BD Pharmingen), and cyclin B1 (Santa Cruz Biotechnology). The blots were washed three times with TBST and incubated with the appropriate horseradish peroxidase-conjugated secondary antibody (Cell Signaling Technology) for $1 \mathrm{~h}$. Blots were washed again and detected with the use of an enhanced chemiluminescence system (Amersham).

Statistical analysis. All the results are expressed as the mean $\pm \mathrm{SD}$ of at least three separate experiments. Statistical comparison between the experimental groups was performed with the Student's t-test. A value of $\mathrm{p}<0.05$ was considered significant.

\section{Results}

GDE increases the anti-proliferative and cytotoxic effects of $\gamma$-irradiation. We investigated the effects of GDE on the cytotoxicity of $\gamma$-irradiation in HL-60 cells. As HL-60 cells do not form appreciable colonies, we monitored their survival by trypan blue exclusion. We treated the HL-60 cells with GDE at least $1 \mathrm{~h}$ before irradiation, irradiated the cells with the clinically relevant dose of $2 \mathrm{~Gy}$, and then incubated them for $48 \mathrm{~h}$. As shown in Fig. 1A, $\gamma$-irradiation (2 Gy) reduced the total number of cells to $68 \%$. GDE further decreased the total number of cells to $29 \%$ compared with untreated controls. Concordant results were obtained when cell proliferation was monitored at $48 \mathrm{~h}$ by MTS assay (data not shown). The effect of GDE+2 Gy irradiation was similar to $\sim 5$ Gy irradiation alone (data not shown), suggesting an enhancement of the radiation effect by GDE pretreatment. Short-term assays or assays of apoptosis alone cannot be expected to measure overall cell death, as defined by the inability of a cell to continue unlimited proliferation, and defined operationally as the ability to form a colony. To establish the long-term proliferation effects of the combination of GDE and radiation on viable cell numbers, we also performed a clonogenic assay as an end point for cytotoxicity, in which not just apoptosis but all the parameters related to cellular growth and death can be simultaneously assessed. We found that HL-60 cells were more sensitive to $\gamma$-irradiation in the presence of GDE. Combined GDE and radiation treatment was estimated to reduce colony formation by $60 \%$, whereas GDE or radiation ( 2 Gy) alone reduced colony formation by 40 and $24 \%$, respectively (Fig. 1B). Taken together, our results illustrate that GDE can increase the anti-proliferative effect and cytotoxicity of $\gamma$-irradiation in HL-60 cells.

Combined treatment with GDE and radiation enhances apoptosis and micronuclei formation in HL-60 cells. Cell 
$\mathbf{A}$

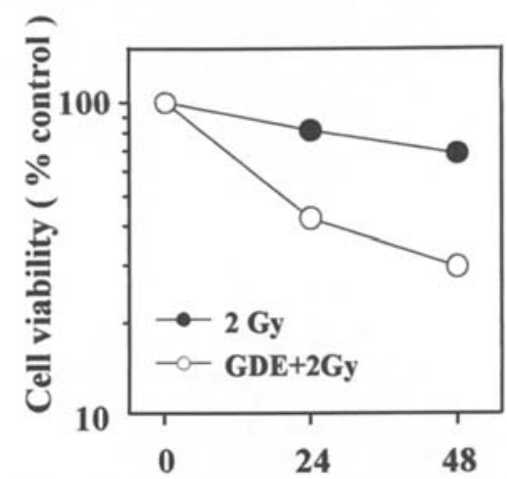

Time after irradiation (h)
B

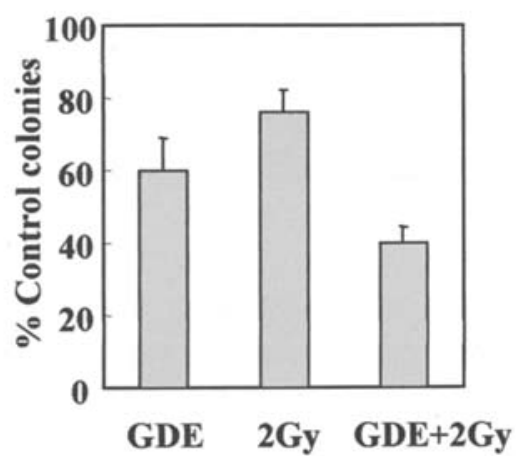

Figure 1. GDE increases the antiproliferative and cytotoxic effects of $\gamma$-irradiation in HL-60 cells. Cells were treated with radiation ( 2 Gy) alone, or the combination of $150 \mu \mathrm{g} / \mathrm{ml}$ Ganoderma extract plus $100 \mu \mathrm{g} / \mathrm{ml}$ Duchesnea extract (GDE) and radiation (GDE+2 Gy). (A) Effects of GDE and radiation on the viability of HL-60 cells. Cell viability was determined by trypan blue exclusion. Points are the mean of at least four separate experiments. (B) The number of colony-forming units of HL-60 cells after exposure to GDE, radiation, or GDE plus radiation. After treatment, the cells were plated in soft agar as described in Materials and methods. After 10-12 days of incubation, the colonies were scored, and colony formation for each condition was expressed relative to untreated control cells. Values represent the mean \pm SD for three separate experiments.

A

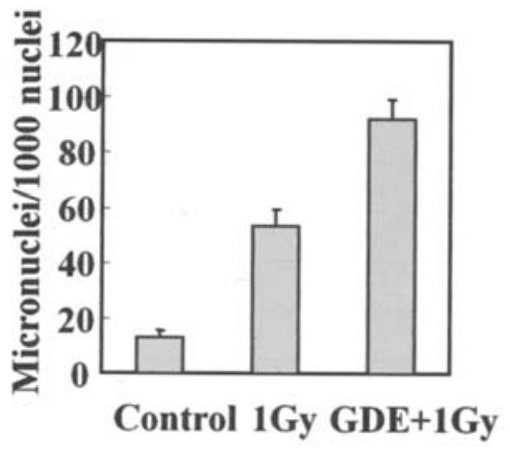

B

$24 \mathrm{~h}$
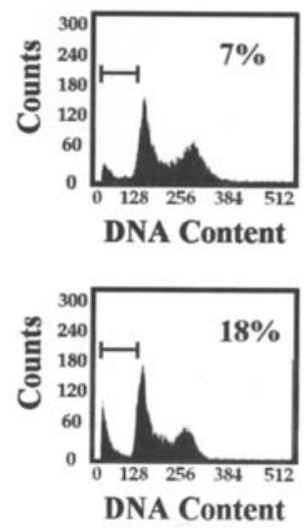
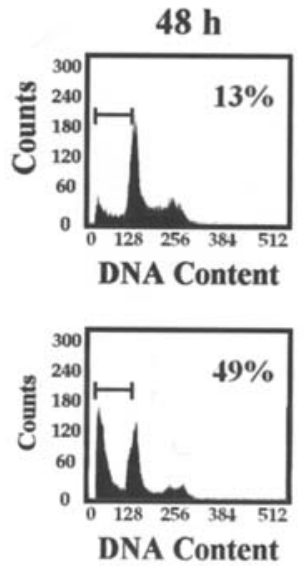

2Gy

GDE+2Gy

Figure 2. Combined treatment with GDE and radiation enhances apoptosis and micronuclei formation in HL-60 cells. (A) Micronuclei frequency in HL-60 cells irradiated in the presence or absence of GDE. Cells were treated with radiation (1 Gy) alone, or the combination of $100 \mu \mathrm{g} / \mathrm{ml}$ Ganoderma extract plus $75 \mu \mathrm{g} / \mathrm{ml}$ Duchesnea extract (GDE) and radiation (GDE+1 Gy), and harvested $48 \mathrm{~h}$ after irradiation. Micronuclei were analyzed as described in Materials and methods and reported per 1,000 nuclei. (B) Flow cytometric analysis of hypodiploid cells after irradiation with or without GDE. Cells were treated with radiation (2 Gy) alone, or the combination of $150 \mu \mathrm{g} / \mathrm{ml}$ Ganoderma extract plus $100 \mu \mathrm{g} / \mathrm{ml}$ Duchesnea extract (GDE) and radiation (GDE+2 Gy). The percentage of the apoptotic cells was assessed by flow cytometry.

death in response to irradiation occurs more frequently as a result of mitotic death, because of irreparable chromosome damage (1). Therefore, we examined the induction of micronuclei frequency in HL-60 cells treated with IR or the combination of GDE and IR. As shown in Fig. 2A, we found that 1 Gy alone led to a 4.1 -fold increase in micronuclei frequency compared with the basal level in the unirradiated control cells. This effect was more prominent in the case of GDE combined with radiation (7.1-fold), suggesting an increase in toxicity for the combined treatment compared with IR alone. We next investigated whether the reduced clonogenic survival by combined treatment of GDE and $\gamma$-radiation was associated with the induction of apoptosis. Flow cytometric analysis after PI staining was performed to evaluate the extent of apoptosis. There was a significant difference in the level of apoptosis after irradiation in the presence and absence of GDE (49 compared with 13\%; Fig. 2B). Treating cells with GDE alone resulted in about $30 \%$ of the cells undergoing apoptosis after $48 \mathrm{~h}$ of treatment (14). Combining GDE with 2 Gy of $\gamma$-radiation increased the 


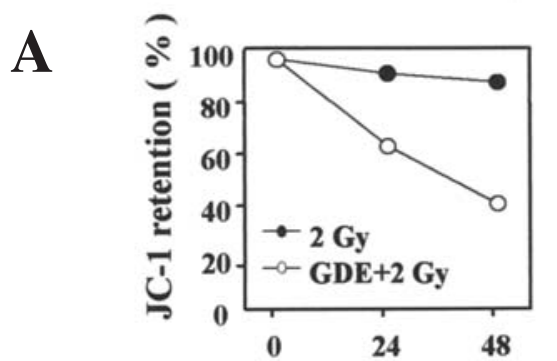

Time after irradiation (h)

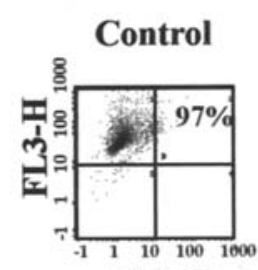

FL1-H

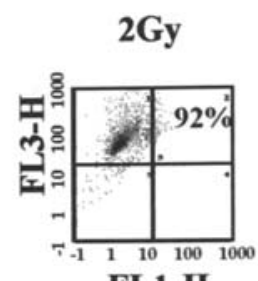

FL1-H

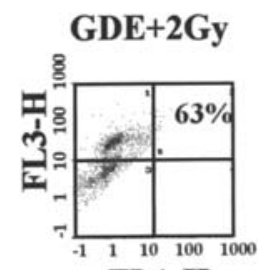

FL1-H

B

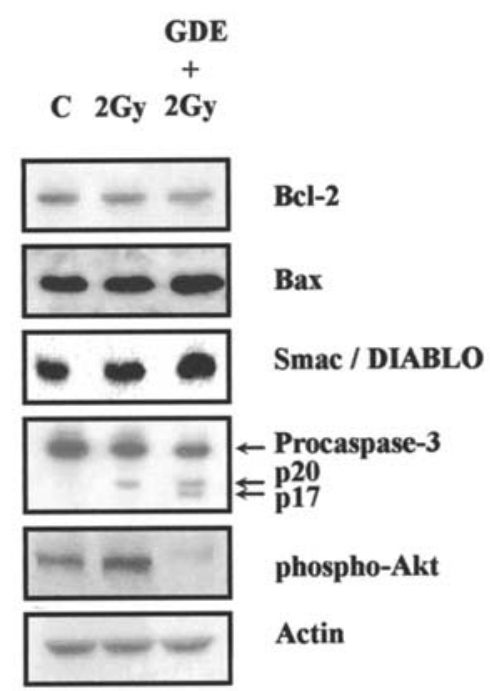

C

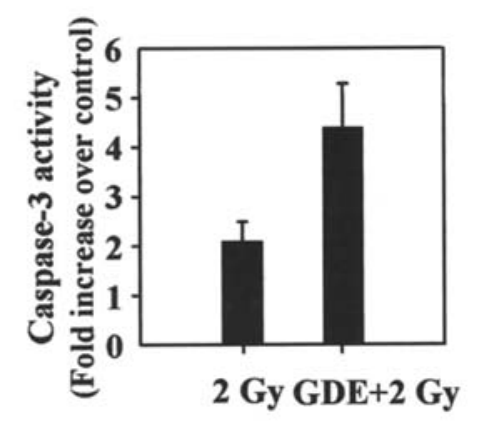

Figure 3. GDE/IR-mediated apoptosis is associated with mitochondrial damage and caspase-3 activation. Cells were treated with radiation (2 Gy) alone, or the combination of $150 \mu \mathrm{g} / \mathrm{ml}$ Ganoderma extract plus $100 \mu \mathrm{g} / \mathrm{ml}$ extract (GDE) and radiation (GDE+2 Gy), and harvested $48 \mathrm{~h}$ after irradiation. (A) Changes in mitochondrial membrane potential over time (left) and quantitative analysis of changes in mitochondrial membrane potential at $24 \mathrm{~h}$ after treatment (right) were examined by measuring the ability to retain JC-1. Numbers indicated in each graph are percentages of red fluorescence (FL3), which reflects functioning mitochondria. (B) Expression of apoptosis-regulating proteins. Expression of Bcl-2, Bax, procaspase-3 cleavage, and phospho-Akt was analyzed by Western blotting with the use of whole-cell lysate. Western blotting detection of Smac/DIABLO protein was observed in the cytoplasmic fraction. (C) A caspase-3 activity assay was performed as described in Materials and methods, and expressed as a fold increase over untreated control. Values represent the mean of at least six separate experiments.

amount of apoptosis to $49 \%$, resulting in an additive increase in apoptosis. These results were further evaluated by annexin V/PI analysis, which distinguishes between early apoptosis (in which cells stain positively for annexin V) and late apoptosis (in which cells stain positively for both annexin $\mathrm{V}$ and PI). It is noteworthy that at later time points (e.g. 36-48 h after exposure), a marked increase in late apoptosis was observed in cells treated with GDE and IR (data not shown). In accordance with these results, exposure to GDE with IR for 24-48 $\mathrm{h}$ resulted in a marked loss of mitochondrial membrane potential (Fig. 3A), a hallmark of mitochondrial injury. Thus, the combined exposure of human leukemia cells to GDE and to IR resulted in a dramatic increase in mitochondrial injury. The effects of exposure of HL-60 cells to IR with or without GDE were then examined in relation to the expression of proteins implicated in mitochondrial injury and apoptotic regulation. Co-exposure of cells to GDE in combination with IR resulted in an increase in levels of the pro-apoptotic proteins Smac/DIABLO and Bax, but no change in the expression of Bcl-2 (Fig. 3B). The status of caspase-3 protein, a key protease in the pathway to apoptosis, was also examined, because caspase- 3 is activated by cleavage from the $32-\mathrm{kDa}$ proenzyme to the active $20-\mathrm{kDa}$ and $17-\mathrm{kDa}$ subunits during apoptosis (19). As shown in Fig. 3B, both the partially processed $(20 \mathrm{kDa})$ and fully processed $(17 \mathrm{kDa})$ forms of caspase- 3 were clearly observed at $48 \mathrm{~h}$ after irradiation in the presence of GDE. Moreover, the relative activity of caspase-3 was increased 4.4-fold at $48 \mathrm{~h}$ after GDE+2 Gy of IR treatment compared with 2.1-fold after 2 Gy alone (Fig. 3C). These data indicate that treatment with this combination induces apoptosis through the mitochondrial intrinsic pathway.

One of the most important survival signaling pathways is mediated by phosphoinositide-3 kinase (PI3K) and its downstream target Akt (20). Recent studies have identified PI3K and Akt signaling as likely contributors to enhanced radiation survival (21). We investigated the effect of GDE on 

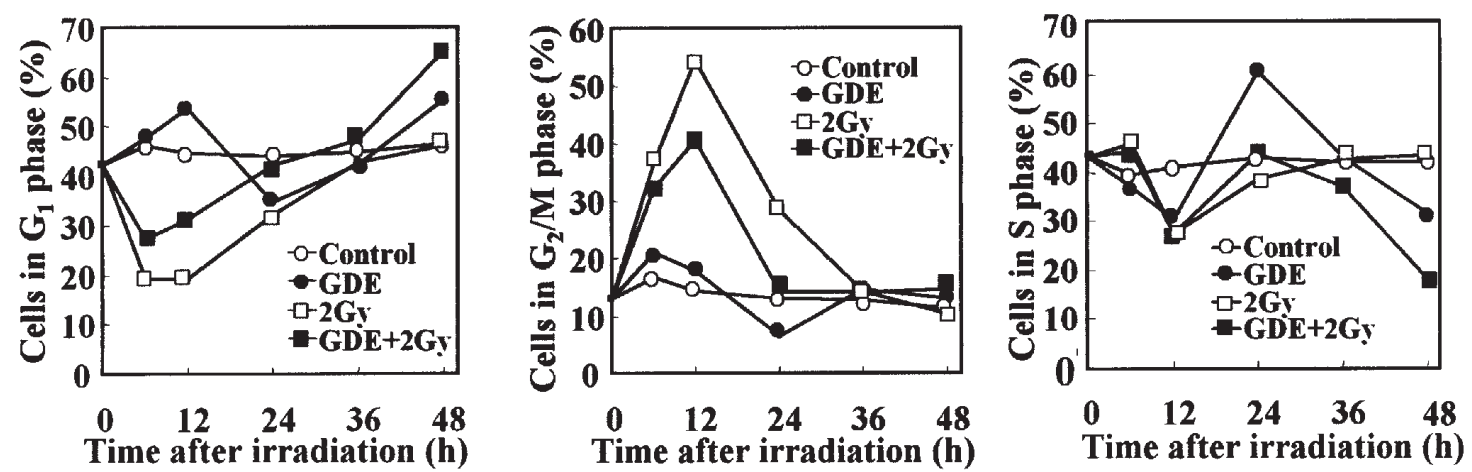

Figure 4. Comparison of the cell-cycle distribution of HL-60 cells irradiated with 2 Gy in the presence or absence of GDE. Cells were treated with $150 \mu \mathrm{g} / \mathrm{ml}$ Ganoderma extract plus $100 \mu \mathrm{g} / \mathrm{ml}$ Duchesnea extract (GDE), radiation (2 Gy) alone, or the combination of GDE and radiation (GDE+2 Gy), and then collected at designated times for DNA content analysis with the use of flow cytometry. Data represent the mean of six independent experiments.

Akt activation after radiation exposure. Although irradiation left phospho-Akt levels unchanged or even increased phospho-Akt levels, treatment with GDE in combination with IR strongly reduced levels of active Akt (Fig. 3B). Our data suggest a role for the inhibition of Akt-mediated antiapoptotic signaling in the increased efficacy of the combination.

GDE blocks cells in $G_{1}$ phase and releases $\gamma$-radiationinduced $G_{2}$-phase arrest. We also compared the cell-cycle redistribution of HL-60 cells irradiated with 2 Gy in the presence and absence of GDE. To determine the cell-cycle response of HL-60 cells to the clinically relevant dose of $2 \mathrm{~Gy}$, we used flow cytometric analysis of DNA content. As shown in Fig. 4, IR (2 Gy) clearly induced a transient arrest in $\mathrm{G}_{2} / \mathrm{M}$ that was first detected $6 \mathrm{~h}$ after treatment and was most pronounced at $12 \mathrm{~h}$ in cells. By $36 \mathrm{~h}$, the percentage of $\mathrm{G}_{2} / \mathrm{M}$ phase cells returned to baseline values. In contrast, the fraction of cells in $\mathrm{G}_{2} / \mathrm{M}$ phase at $12-24 \mathrm{~h}$ after irradiation was reduced by approximately $23-47 \%$ in the cells treated with GDE relative to the cells treated with radiation only. Furthermore, the $\mathrm{G}_{2} / \mathrm{M}$ arrest was no longer apparent at $24 \mathrm{~h}$ after irradiation, suggesting alteration of the level and the duration of $\mathrm{G}_{2} / \mathrm{M}$-phase arrest by GDE pretreatment. It is noteworthy that at a later time point (i.e. $48 \mathrm{~h}$ ), GDE treatment induced accumulation of cells in $G_{1}$ in unirradiated controls and reduced the number of cells in $\mathrm{S}$ phase. When combined with radiation, GDE increased the number of cells in $G_{1}$ phase, with a further reduction in the S-phase fraction (Fig. 4). Taken together, these results show that the treatment of HL-60 cells with GDE not only induces cell-cycle arrest in the $\mathrm{G}_{1}$ phase, but also inhibits the radiation-induced $\mathrm{G}_{2}$-phase checkpoint.

GDE induces dephosphorylation of retinoblastoma protein $(p R B)$ and inhibits the phosphorylation of cyclin-dependent kinase 1 (CDK1) in irradiated HL-60 cells. To investigate the mechanism through which IR-induced $\mathrm{G}_{2} / \mathrm{M}$ arrest is abrogated by GDE, proteins related to the $G_{2} / M$ and $G_{1}$ cellcycle checkpoints were evaluated. As pRB functions as a regulator of cell-cycle progression at the late $G_{1}$ phase (22), and because $\mathrm{G}_{1}$ cyclin and cyclin-dependent kinases (CDKs) can regulate the activity of $\mathrm{pRB}$, we examined the effects of GDE and $\mathrm{IR}$ on $\mathrm{G}_{1} \mathrm{CDK}$ expression and $\mathrm{pRB}$ phosphorylation. As shown in Fig. 5A, Western blot analysis using an antibody specific for the under-phosphorylated form of $\mathrm{pRB}$ revealed that the level of the under-phosphorylated form of $\mathrm{pRB}$ increased markedly in GDE-treated HL-60 cells at $48 \mathrm{~h}$ after irradiation, suggesting that GDE may inhibit HL-60 cells through the inhibition of pRB phosphorylation. Fig. 5A also shows that GDE treatment resulted in a marked decrease in the protein expression of CDK2 and cyclin E. These results suggest that CDK2 and cyclin $\mathrm{E}$ are major targets of GDE action in HL-60 cells, which may be, at least in part, responsible for the inhibition of GDE-induced $\mathrm{pRB}$ phosphorylation. CDK inhibitors, including p21(WAF1/CIP1), p27(Kip1), and p16(Ink4), also contribute to the regulation of cell-cycle progression by controlling CDK activity. p21 inhibits a wide variety of cyclin-CDK complexes in vitro, including CDK4 and CDK2 complexes. In addition, the overexpression of these proteins blocks the progression of cells through $\mathrm{G}_{1}$ (23). In our assay system, p21 was expressed in irradiated HL-60 cells at a moderate level and did not show obvious response to GDE treatment (data not shown), indicating that $\mathrm{p} 21$ is not involved in the GDE inhibition of cell growth in HL-60 cells. Taken together, these findings indicate that GDE can inhibit the growth of human leukemia HL-60 cells through the induction of $\mathrm{G}_{1}$ cell-cycle arrest caused by the inhibition of pRB phosphorylation.

Radiation-induced $\mathrm{G}_{2}$-phase arrest involves a mechanism of cyclin B1/CDK1 kinase inhibition $(24,25)$. The cyclin B1/CDK1 kinase activity depends on the availability of cyclin B1 and the phosphorylation status of CDK1 $(26,27)$. The localization of cyclin B1 may also contribute to its regulation (28). As the GDE used in this study had effects on the radiation-induced $\mathrm{G}_{2}$ phase, we examined the levels of cyclin B1 protein in the nucleus and cytoplasm after radiation treatment in the presence or absence of GDE. As shown in Fig. 5B, a 2-Gy dose of radiation stimulated the nuclear accumulation of cyclin B1. Cyclin B1 localized to the nucleus in HL-60 cells within $2 \mathrm{~h}$ of radiation exposure. The cyclin B1 level in the nucleus was still increased, relative to the control, up to $24 \mathrm{~h}$ after radiation. In the irradiated cells 
A

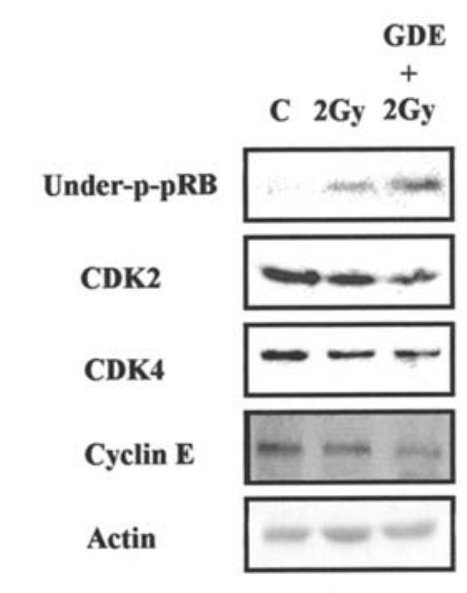

B

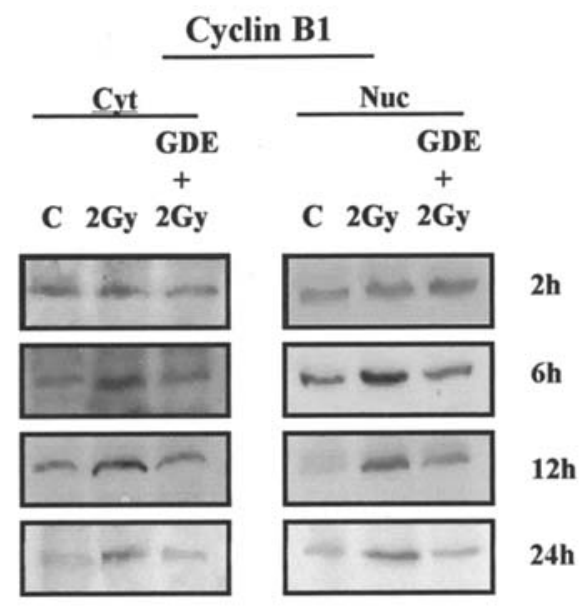

\section{C}

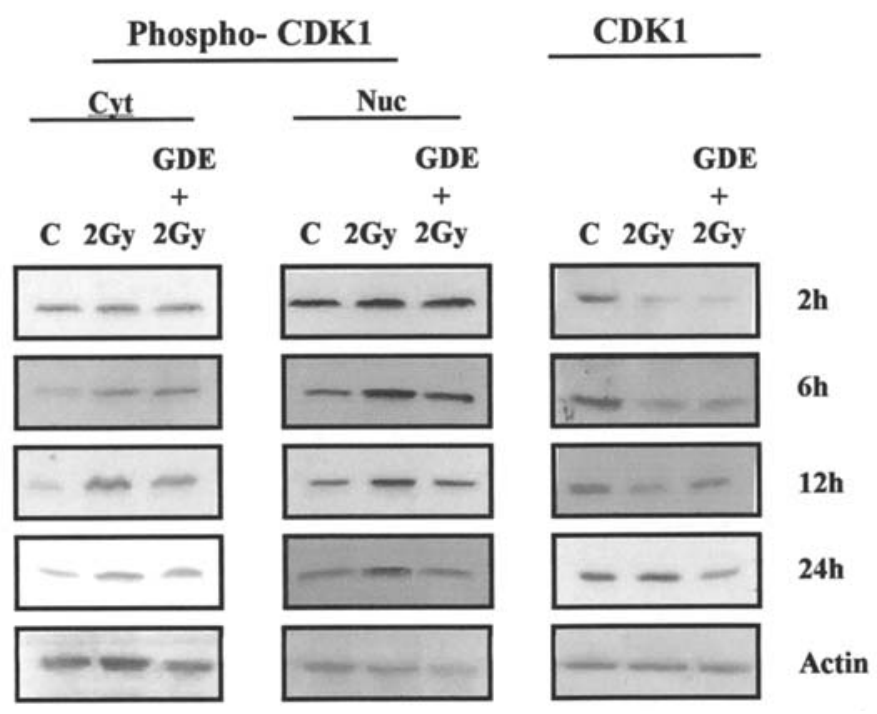

Figure 5. Expression of cell-cycle-regulating proteins in HL-60 cells irradiated with or without GDE. Cells were treated with radiation (2 Gy) alone, or the combination of $150 \mu \mathrm{g} / \mathrm{ml}$ Ganoderma extract plus $100 \mu \mathrm{g} / \mathrm{ml}$ Duchesnea extract (GDE) and radiation (GDE+2 Gy). (A) Expression of under-phosphorylated pRB (Under-p-pRB), CDK4, CDK2, and cyclin E was analyzed by Western blotting with the use of whole-cell lysate $48 \mathrm{~h}$ after irradiation. Western blotting detection of cyclin B1 (B) and Tyr-15-phosphorylated CDK1 (C) protein at subcellular levels was observed both in the cytoplasmic (Cyt) and nuclear (Nuc) fractions. Expression of total CDK1 (C) was observed in whole-cell fraction at each of the indicated time points. Results are representative of three separate experiments.

with GDE, however, the levels of cyclin B1 protein decreased, relative to cells treated only with radiation, at $12 \mathrm{~h}$ after radiation, corresponding to the beginning of the exit of the cells from the radiation-induced $\mathrm{G}_{2}$ block. At $24 \mathrm{~h}$ after radiation, by which time cyclin $\mathrm{B} 1$ had returned to control levels, there was little evidence of $\mathrm{G}_{2} / \mathrm{M}$ arrest (Fig. 4). These findings support the suggestion that, although the presence of cyclin B1 is required for entry into mitosis, its destruction is required for exit from mitosis (29). These data show that, at a clinically relevant dose of IR (2 Gy), GDE inhibits the radiation-induced $\mathrm{G}_{2}$ checkpoint in HL-60 cells. Although nuclear localization of cyclin B1 controls mitotic entry after DNA damage, the nuclear localization of cyclin B1 alone is insufficient to trigger premature mitotic events (29). Previous reports indicate that Tyr-15 phosphorylation of CDK1 is required to arrest cells in $\mathrm{G}_{2}$ in response to radiation (30). To examine the mechanism by which $\gamma$-radiation inhibited CDK1 activity, we determined the phosphorylation status of CDK1 in the nucleus and cytoplasm by using an antibody specific for the phosphotyrosine 15 form of CDK 1 . Irradiation led to the marked nuclear accumulation of Tyr-15phosphorylated CDK1 protein. As shown in Fig. 5C, the 
level of the tyrosine-phosphorylated CDK1 protein in the nucleus increased up to $24 \mathrm{~h}$ after irradiation; this effect was attenuated by GDE pretreatment. Our results demonstrate that GDE can inhibit IR-induced CDK1 phosphorylation, which could account for, or contribute to, the reduction of cell proportion in the radiation-induced $\mathrm{G}_{2} / \mathrm{M}$ phase (Fig. 4). Taken together, these findings indicate that GDE induces the dephosphorylation of $\mathrm{pRB}$ and inhibits the phosphorylation of CDK1 in irradiated HL-60 cells.

\section{Discussion}

In the current study, we evaluated the therapeutic effect of GDE combined with radiation in human leukemia HL-60 cells. Our results showed that the combined treatment with GDE and $\gamma$-radiation is more cytotoxic than radiation alone. Further analyses revealed that GDE pretreatment enhances the radiation-induced cell death of human leukemia HL-60 cells in vitro by affecting the cell cycle and by inducing apoptosis. A similar result was observed even when GDE was added several hours after irradiation, although the magnitude of the response was lower (data not shown). These findings suggest that GDE could be useful as a cytotoxic agent in combination with radiation.

To investigate the potential mechanisms and genes that may be involved in these processes, we examined several regulatory proteins associated with the cell cycle and radiation-induced apoptosis. The induction of apoptosis has been linked to mitochondrial damage, including loss of the mitochondrial membrane potential or release of pro-apoptotic proteins from the mitochondria, such as cytochrome $\mathrm{c}$ and Smac/DIABLO (31), a pro-apoptotic protein that acts by antagonizing the actions of members of the XIAP family of caspase inhibitors (32). The present findings clearly show that Ganoderma/Duchesnea-induced apoptosis in irradiated cells is associated with a change in mitochondrial membrane potential, Bax induction, Smac/DIABLO release, and caspase-3 activation, suggesting that apoptosis by this combination occurs through the mitochondria-dependent pathway. Such findings are consistent with previous reports demonstrating that Bax overexpression produces cell death upon induction of mitochondrial permeability transition (33) and that mitochondrial levels of Bcl-2 family proteins may determine the sensitivity of leukemic cells to apoptosis (34).

In addition to pro- and anti-apoptotic proteins (35), apoptosis is also regulated by multiple signal transduction cascades. Recently, the Ras/PI3K/Akt signal transduction pathway has become the focus of intense interest as a critical regulator of cell survival/death decision (36). More recent studies have demonstrated that Akt maintains mitochondrial integrity by increasing hexokinase association with mitochondria, and inhibits apoptosis by preventing changes in the permeability of the outer mitochondrial membrane and cytochrome c release after exposure to apoptotic stimuli (37). We can identify Akt as an important target of the proapoptotic effects of GDE upstream of the mitochondria. Although irradiation increased the level of active Akt, treatment with GDE before radiation strongly inhibited the activation of Akt in irradiated HL-60 cells, as indicated by the reduced expression of phosphorylated Akt at serine-473
(Fig. 3B). It is, therefore, possible that Akt inhibition by GDE could contribute to the potentiation of IR-mediated apoptosis. However, further studies are required to define the multiple mechanisms by which GDE modulates the PI3K/Akt pathway signaling.

Apoptosis is a common mode of cell death after the exposure of tumor cells to radiation and/or chemotherapy. On the other hand, there is also evidence suggesting that apoptosis does not always affect clonogenic survival. Previous studies have shown that apoptosis alone is not sufficient to explain all of the radiation-induced loss of clonogenic survival in HL-60 cells (38-40). Moreover, in a review of the effect of radiation on normal and malignant tissues, Gudkov and Komarova (41) demonstrated that apoptosis has a relatively modest role in the tumor response to radiation; most tumors lose the ability to induce apoptosis. Furthermore, although in the present study, GDE by itself resulted in a marked increase in apoptosis in HL-60 cells, the connection between clonogenic cell death and apoptosis by GDE alone was not apparent, as in the case of GDE combined with radiation (Fig. 1B). Using a clonogenic assay, we confirmed that GDE combined with radiation caused greater inhibition in HL-60 colony formation compared with GDE or radiation alone. Cellular death induced by ionizing radiation includes both apoptosis and mitosis-linked death, as well as the loss of reproductive capacity. The most frequent mode of cell death after irradiation is mitosis-linked death (42), which is associated with micronuclei formations. Micronuclei are formed from the nuclear membrane encapsulation of chromatin and chromosomal fragments that fail to properly segregate after mitosis (43). Using a micronuclei assay, we found that radiation exposure of GDEtreated cells further enhanced micronuclei formation. Furthermore, combined treatment with GDE and IR (1 Gy) was effective in inducing micronuclei even at lower doses than those used to induce apoptosis. These data suggest that the increased cell death by the combined treatment could be accounted for by the sum of the micronucleated and apoptotic cells in the irradiated population. This observation is in agreement with Abend et al (39), who found that for three cell lines, including HL-60, the summation of two kinds of cellular damage, micronuclei production and apoptosis, correlated well with cell clonogenic survival.

The mechanism by which this enhanced effect was produced was determined by cell-cycle analysis. We found that irradiating HL-60 cells in the presence of GDE altered the level and the duration of $\mathrm{G}_{2} / \mathrm{M}$-phase arrest, and affected the sensitivity of the cells to radiation, suggesting that modulation of the $\mathrm{G}_{2} / \mathrm{M}$-phase checkpoint might be useful for sensitizing tumor cells to radiotherapy. Although $\mathrm{G}_{2} / \mathrm{M}$ arrest after exposure to radiation appears to result from multiple mechanisms, it is widely believed that the CDK1/cyclin B1 complex plays a central role (30). During the $\mathrm{G}_{2}$ phase, the CDK1/cyclin B1 complex is held in an inactive state by phosphorylation of CDK1 on threonine 14 and Tyr-15 residues (44). It has been suggested that Tyr-15 has a more significant role in maintaining a $\mathrm{G}_{2}$ arrest after irradiation (30). We demonstrated in this study that GDE can inhibit the radiation-induced phosphorylation of CDK1 on Tyr-15, which may be responsible for the reduction of $\mathrm{G}_{2} / \mathrm{M}$-phase 
arrest. It would appear, therefore, that inhibition of CDK1 phosphorylation by GDE would activate the CDK1 kinase, thereby leading to abrogation of $\mathrm{G}_{2}$ arrest and premature entry into mitosis. This premature entry of cells into mitosis, without the complete repair of DNA damage, increases the likelihood of a lethal mitosis (45). Previous studies suggest that the initiation of abortive mitosis through the premature activation of CDK1 kinase may be a general mechanism for the induction of apoptosis (46). Thus, because $\mathrm{G}_{2}$-phase arrest is considered to be a period of recovery and repair, the attenuation of $\mathrm{G}_{2} / \mathrm{M}$-phase arrest would decrease the opportunity for DNA repair and thereby potentiate radiationinduced cell killing. This hypothesis is supported by the finding that agents that can effectively abrogate the $\mathrm{G}_{2}$ checkpoint result in synergistic cytotoxicity with DNAdamaging agents such as radiation (47-49). However, the role of $\mathrm{G}_{2} / \mathrm{M}$ checkpoint abrogation as a mechanism to potentiate radiotherapy remains controversial, although the $G_{2}$ checkpoint abrogation as a therapeutic target appears to be very promising.

On the other hand, the inhibition of cell-cycle progression is considered a potential therapy for various cancers (50). In addition to the dysregulation of the $G_{2}$ phase, we found that GDE induced a $G_{1}$-phase arrest. Further analyses revealed that accumulation of an under-phosphorylated form of $\mathrm{pRB}$ by GDE accompanied $\mathrm{G}_{1}$ arrest in HL-60 cells (Figs. 4 and $5 A)$. Here we demonstrated that this $\mathrm{G}_{1}$-phase arrest appears to be due to the reduction of the $\mathrm{G}_{1}$-related CDK2 and cyclin $\mathrm{E}$, which may be responsible for the inhibition of pRB phosphorylation. These data are consistent with the view that $\mathrm{pRB}$ dephosphorylation is required for $\mathrm{G}_{1}$ arrest in p53-negative cells (51). Our data show that GDE induced pRB dephosphorylation, $\mathrm{G}_{1}$ arrest, and apoptosis in irradiated HL-60 cells. As the p53-independent apoptosis is tightly associated with $\mathrm{G}_{1}$ arrest $(51,52)$, it is possible that pRB dephosphorylation by GDE might also be involved in regulating programmed cell death in these cells.

In conclusion, our study shows that GDE pretreatment sensitizes cancer cells to radiation-induced growth inhibition and apoptosis. Furthermore, the enhanced induction of mitochondrial damage and apoptosis by this combination was also observed in IR-treated U-937 monocytic leukemia cells (data not shown). We also found that, although GDE pretreatment failed to enhance IR-mediated apoptosis in multiple solid tumor cell lines, including HT-1080, MCF-7, HT-29 and A549 cells, it did lead to a significant reduction in proliferation in cancer cell lines irradiated with $\gamma$-radiation (our unpublished data). This finding indicates that our treatment strategy could be more broadly applied to cancer therapy. Importantly, GDE-induced radiosensitization was observed in combination with a clinically relevant dose of $2 \mathrm{~Gy}$. These results suggest that the combination tactic could be more potent than each modality alone. These extracts have been shown to be safe when taken over long treatment periods, and more significantly, they appear to reduce the adverse effects of radiotherapy. Taken together, these findings may be relevant to the clinical application of a combination therapy of GDE and radiation, and represent a novel therapeutic strategy for increasing the efficacy of radiotherapy.

\section{Acknowledgements}

This work was funded by the Nuclear Research and Development Program of the Ministry of Science and Technology of the Republic of Korea.

\section{References}

1. Cohen-Jonathan E, Bernhard EJ and McKenna WG: How does radiation kill cells? Curr Opin Chem Biol 3: 77-83, 1999.

2. Ghia P and Nadler LM: Recent advances in lymphoma biology. Curr Opin Oncol 9: 403-412, 1997.

3. Okada H and Mak TW: Pathways of apoptotic and nonapoptotic death in tumour cells. Nature Rev Cancer 4: 592-603, 2004.

4. Mias L, Mason KA, Liao Z and Ang KK: Chemoradiotherapy: Emerging treatment improvement strategies. Head Neck 25: 152-167, 2003.

5. Colevas AD, Brown AM, Hahn S, Mitchell J, Camphausen K and Coleman CN: Development of investigational radiation modifiers. J Nat Cancer Inst 95: 646-651, 2003.

6. Belka C, Jendrossek V, Pruschy M, Vink S, Verheij M and Budach W: Apoptosis-modulating agents in combination with radiotherapy-current status and outlook. Int J Radiat Oncol Biol Phys 58: 542-554, 2004.

7. Lin ZB and Zhang HN: Anti-tumor and immunoregulatory activities of Ganoderma lucidum and its possible mechanism. Acta Pharmacol Sinica 25: 1387-1395, 2004.

8. Jong SC and Birmingham JM: Medicinal benefits of the mushroom Ganoderma. Adv Appl Microbiol 37: 101-134, 1992.

9. Wasser SP and Weis AL: Therapeutic effects of substances occurring in higher Basidiomycetes mushrooms: a modern perspective. Crit Rev Immunol 19: 65-96, 1999.

10. Sliva D, Labarrere C, Slivova V, Sedlak M, Lloyad FP Jr and Ho NWY: Ganoderma lucidum suppresses motility of highly invasive breast and prostate cancer cells. Biochem Biophys Res Commum 298: 603-612, 2002.

11. Jiang J, Slivova V, Valachovicova T, Harvey K and Sliva D: Ganoderma lucidum inhibits proliferation and induces apoptosis in human prostate cancer cells PC-3. Int J Oncol 24: 1093-1099, 2004.

12. Kim IG, Jung IL, Oh TJ, Kim KC and Shim HW: Polysaccharideenriched fraction isolated from Duchesnea chrysantha protects against oxidative damage. Biotechnol Lett 24: 1299-1305, 2002.

13. Lee IR and Yang MY: Phenolic compounds from Duchesnea chrysantha and their cytotoxic activities in human cancer cell. Arch Pharm Res 17: 476-479, 1994.

14. Kim KC, Kim JS, Son JK and Kim IG: Enhanced induction of mitochondrial damage and apoptosis in human leukemia HL-60 cells by the Ganoderma lucidum and Duchesnea chrysantha extracts. Cancer Lett 246: 210-217, 2007.

15. Zhu M, Chang Q, Wong LK, Chong FS and Li RC: Triterpene antioxidants from Ganoderma lucidum. Phytother Res 13: 529-531, 1999.

16. Wang SY, Chen LY, Wang SJ, Lin CK and Ho CK: Growth inhibition and differentiation in HL-60 leukemia cells induced by 1,25-dihydroxyvitamin $\mathrm{D}_{3}$ and tumor necrosis factor alpha. Exp Hematol 19: 1025-1030, 1991.

17. Eckhardt SG, Dai A, Davidson KK, Forseth BJ, Wahl GM and Von Hoff DD: Induction of differentiation in HL60 cells by the reduction of extrachromosomally amplified c-myc. Proc Natl Acad Sci USA 91: 6674-6678, 1994.

18. Bradbury DA, Simmons TD, Slater KJ and Crouch SPM: Measurement of ADP:ATP ratio in human leukaemic cell lines can be used as an indicator of cell viability, necrosis and apoptosis. J Immunol Methods 240: 79-92, 2000.

19. Sun XM, Bratton SB, Butterworth M, MacFarlane M and Cohen GM: Bcl-2 and Bcl- $\mathrm{x}_{\mathrm{L}}$ inhibit CD95-mediated apoptosis by preventing mitochondrial release of Smac/DIABLO and subsequent inactivation of X-linked inhibitor-of-apoptosis protein. J Biol Chem 277: 11345-11351, 2002.

20. Franke T and Kaplan D: PI3K: Downstream AKTion blocks apoptosis. Cell 88: 435-437, 1997.

21. McKenna WG and Muschel RJ: Targeting tumor cells by enhancing radiation sensitivity. Genes Chromosomes Cancer 38: 330-338, 2003.

22. Weinberg RA: The retinoblastoma protein and cell cycle control. Cell 81: 323-330. 1995. 
23. Hunter T and Pines J: Cyclins and cancer II: Cyclin D and CDK inhibitors come of age. Cell 79: 573-582, 1994.

24. Paules RS, Levedakou EN, Wilson SJ, Innes CL, Rhodes N, Tlsty TD, Galloway DA, Donehower LA, Tainsky MA and Kaufmann WK: Defective $G_{2}$ checkpoint function in cells from individuals with familial cancer syndromes. Cancer Res 55: 1763-1773, 1995.

25. Kaufmann WK, Levedakou EN, Grady HL, Paules RS and Stein $\mathrm{GH}$ : Attenuation of $\mathrm{G}_{2}$ checkpoint function precedes human cell immortalization. Cancer Res 55: 7-11, 1995.

26. Hwang A and Muschel RJ: Radiation and the $G_{2}$ phase of the cell cycle. Radiat Res 150: S52-S59, 1998.

27. Kao GD, McKenna WG, Maity A, Blank K and Muschel RJ: Cyclin B1 availability is a rate-limiting component of the radiation-induced $\mathrm{G}_{2}$ delay in HeLa cells. Cancer Res 57: 753-758, 1997.

28. Yang J and Kornbluth S: All about the cyclin train: subcellular trafficking of cyclins and their CDK partners. Trends Cell Biol 9: 207-210, 1999

29. Jin P, Hardy S and Morgan DO: Nuclear localization of cyclin B1 controls mitotic entry after DNA damage. J Cell Biol 141: 875-885, 1998.

30. Fletcher L, Cheng Y and Muschel RJ: Abolishment of the Tyr-15 inhibitory phophorylation site on cdc2 reduces the radiationinduced $\mathrm{G}_{2}$ delay, revealing a potential checkpoint in early mitosis. Cancer Res 62: 241-250, 2002.

31. Chauhan D, Hideshima T, Rosen S, Reed JC, Kharbanda S and Anderson KC: Apaf-1/cytochrome c-independent and Smacdependent induction of apoptosis in multiple myeloma (MM) cells. J Biol Chem 276: 24453-24456, 2001.

32. Wu G, Chai J, Suber TL, Wu JW, Du C, Wang X and Shi Y: Structural basis of IAP recognition by Smac/DIABLO. Nature 408: 1008-1012, 2000

33. Pastorino JG, Chen S-T, Tafani M, Snyder JW and Farber JL: The overexpression of Bax produces cell death upon induction of the mitochondrial permeability transition. J Biol Chem 273: 7770-7775, 1998

34. Jia L, Macey MG, Yin T, Newland AC and Kelsey SM: Subcellular distribution and redistribution of Bcl-2 family proteins in human leukemia cell undergoing apoptosis. Blood 93: 2353-2359, 1999.

35. Reed JC: Bcl-2 family proteins. Oncogene 17: 3225-3236, 1998.

36. Cantley LC: The phosphoinositide 3-kinase pathway. Science 296: 1655-1657, 2002.

37. Majewski N, Nogueira V, Bhaskar P, Coy PE, Skeen JE, Gottlob K, Chandel NS, Thompson CB, Robey RB and Hay N: Hexokinase-mitochondria interaction mediated by Akt is required to inhibit apoptosis in the presence or absence of Bax and Bak. Mol Cell 16: 819-830, 2004.
38. Hopcia KL, McCarey YL, Sylvester FC and Held KD Radiation-induced apoptosis in HL-60 cells: oxygen effect, relationship between apoptosis and loss of clonogenicity, and dependence of time to apoptosis on radiation dose. Radiat Res 145: 315-323, 1996

39. Abend M, Rhein A, Gilbertz KP, Blakely WF and Beuningen DV: Correlation of micronucleus and apoptosis assays with reproductive cell death. Int J Radiat Biol 67: 315-326, 1995.

40. Kumala S, Niemiec P, Widel M, Hancock $\mathrm{R}$ and Rzeszowska-Wolny J: Apoptosis and clonogenic survival in three tumour cells lines exposed to gamma ray or chemical genotoxic agents. Cell Mol Biol Lett 8: 655-665, 2003.

41. Gudkov AV and Komarova EA: The role of $\mathrm{p} 53$ in determining sensitivity to radiotherapy. Nature Rev Cancer 3: 117-129, 2003.

42. Dewey WC, Ling CC and Meyn RE: Radiation-induced apoptosis: relevance to radiotherapy. Int J Radiat Oncol Biol Phys 33: 781-796, 1995.

43. Muller WU, Nusse M, Miller BM, Slavotinek A, Viaggi S and Streffer C: Micronuclei: A biological indicator of radiation damage. Mutat Res 366: 163-169, 1996.

44. Lew DJ and Kornbluth S: Regulatory roles of cyclin dependent kinase phosphorylation in cell cycle control. Curr Opin Cell Biol 8: 795-804, 1996.

45. Erenpreisa J and Cragg MS: Mitotic death: a mechanism of survival? A review. Cancer Cell Int 1: 1, 2001.

46. Shi L, Nishioka WK, Th'ng J, Bradbury EM, Litchfield DW and Greenberg AH: Premature p34 ${ }^{\mathrm{cdc} 2}$ activation required for apoptosis. Science 263: 1143-1145, 1994.

47. Yao SL, Akhtar AJ, McKenna KA, Bedi GC, Sidransky D, Mabry M, Ravi R, Collector MI, Jones RJ, Sharkis SJ, Fuchs EJ and Bedi A: Selective radiosensitization of p53-deficient cells by caffeine-mediated activation of p34 ${ }^{\text {cdc2 }}$ kinase. Nat Med 2: 1140-1143, 1996.

48. Wang Y, Li J, Booher RN, Kraker A, Lawrence T, Leopold WR and Sun Y: Radiosensitization of p53 mutant cells by PD0166285, a novel $\mathrm{G}_{2}$ checkpoint abrogator. Cancer Res 61: 8211-8217, 2001.

49. Mack PC, Jones AA, Gustafsson MH, Gandara DR, Gumerlock PH and Goldberg Z: Enhancement of radiation cytotoxicity by UCN-01 in non-small cell lung carcinoma cells. Radiat Res 162: 623-634, 2004.

50. Collins K, Jacks T and Pavletich NP: The cell cycle and cancer. Proc Natl Acad Sci USA 94: 2776-2778, 1997.

51. Dou QP, An B and Will PL: Induction of a retinoblastoma phosphatase activity by anticancer drugs accompanies p53independent $\mathrm{G}_{1}$ arrest and apoptosis. Proc Natl Acad Sci USA 92: 9019-9023, 1995.

52. Strasser A, Harris AW, Jacks T and Cory S: DNA damage can induce apoptosis in proliferating lymphoid cells via p53independent mechanisms inhibitable by Bcl-2. Cell 79: 329-339, 1994. 